\title{
Los imaginarios urbanos y el constructivismo geográfico: los hologramas espaciales
}

\begin{abstract}
This paper has a methodological orientation (a specific qualitative methodology). It also develops the relationship between the methodological proposal and a theoretical conceptualization of a constructivist type (a geographical constructivism). The first part of the text develops the perspective of the social construction of city places. The second part analyzes the relationship between Urban Imaginaries and the social construction of places. Finally, the third part develops the central point of the article: the methodological challenges of this particular constructivist perspective. To do this, the most frequent approaches are analyzed and their limitations noted. This is followed by the methodological strategy called 'spatial holograms', which seeks to avoid the limitations of traditional approaches although it is not without pitfalls of its own.
\end{abstract}

Keywords: geographical constructivism, place, urban imaginaries, spatial holograms, scenarios

\section{Resumen}

Este artículo tiene un carácter metodológico (una particular metodología cualitativa). No obstante, también se plantea la relación entre la propuesta metodológica y una concepción teórica de tipo constructivista (un constructivismo geográfico). En la primera parte del texto se desarrolla la perspectiva denominada construcción social de los lugares en la ciudad. Luego, en la segunda parte se analiza la relación entre los imaginarios urbanos y la construcción social de los lugares. En la tercera parte se avanza sobre el interés central del artículo: los desafíos metodológicos de esta perspectiva constructivista particular. Para ello, se revisan las aproximaciones más frecuentes y se advierte sobre sus limitaciones. Enseguida, se plantea la estrategia metodológica propia denominada hologramas espaciales, que intenta sortear las limitaciones de las aproximaciones tradicionales aunque no por ello está libre de escollos.

Palabras claves: constructivismo geográfico, lugar, imaginarios urbanos, hologramas espaciales, escenarios 
$\mathrm{L}$

a inclusión de los imaginarios dentro del campo de los Estudios Urbanos, antes que nada representa la apertura de este campo, que tradicionalmente ha estado orientado por enfoques diversos pero casi siempre de tipo objetivista y/o materialista. Dicho de otra forma, los Estudios Urbanos han tendido a preguntarse por la ciudad desde los diversos ángulos de lo material y tangible, en sus cuatro principales dimensiones: la construcción física de la ciudad (con énfasis urbanístico), la distribución de la población dentro de la ciudad (con carácter demográfico), la distribución de los distintos grupos sociales y sus diversas acciones en la ciudad (con un matiz de sociología urbana) o bien, la producción de la riqueza en la ciudad a través de las actividades económicas (con un acento de economía urbana). Seguramente que esas dimensiones han sido y siguen siendo relevantes para entender ese territorio complejo y multidimensional que llamamos ciudad. No obstante, estos sesgos han soslayado otras dimensiones también constitutivas de la ciudad misma y la vida social que la anima, como son todas aquellas vinculadas a las subjetividades compartidas, la intersubjetividad, la cultura urbana, y todo aquello que usualmente se conoce como los imaginarios urbanos. Por eso, nuestro objetivo de fondo es reflexionar acerca de la posibilidad de comprender la ciudad desde los imaginarios urbanos como un proceso de construcción social permanente. Aproximarnos a la comprensión de la ciudad desde este ángulo permite otorgarle inteligibilidad y hacer visibles ciertos procesos y fenómenos urbanos, que las miradas antes comentadas dejan en la penumbra o directamente, invisibilizan (Louiset, 2001).

Con este encuadre esbozado, nuestro interés se orienta de manera más específica hacia los procesos de construcción social del espacio urbano, lo que no debería asimilarse a la construcción material de la ciudad en el sentido de su fabricación por parte del homo faber, sin por ello excluir dicha materialidad y su producción. La construcción social del espacio urbano puede entenderse -siguiendo a Constancio de Castro (1997)- como la manufacturación cultural de la ciudad, aunque

Universidad Autónoma Metropolitana, Iztapalapa, Ciudad de México. E-mail: alicia.lindon@gmail.com tal vez sería más adecuado llamarla manufacturación socio-cultural. El interés por diferenciar la fabricación material de la ciudad y la construcción social del espacio urbano se funda en que la segunda opción -que guía nuestro trabajo- cobra sentido bajo el paraguas amplio del pensamiento constructivista, aunque con la particularidad de concretarse como un constructivismo geográfico. En cambio, la primera opción se limita a estudiar la producción material de la ciudad. Por ejemplo, la producción de vivienda, de infraestructura..... Por cierto, esta es una de las formas de estudiar la ciudad más desarrollada.

La construcción social de los distintos lugares que integran la ciudad, es un proceso constante de manufacturación del espacio que realizan las personas en interacción unas con otras, orientando sus prácticas espaciales a través de una trama de sentido que denominamos imaginarios urbanos, o como diría Francisco Varela: "cada época de la historia humana produce, a través de sus prácticas sociales cotidianas y su lenguaje, una estructura imaginaria" (2006: p. 12). Sobre esta cuestión tratan las páginas siguientes.

Para desarrollar esta aproximación, en la primera parte del texto se esclarece el sentido que le damos a la expresión construcción social de los lugares en la ciudad. Luego, en la segunda parte analizamos de qué forma los imaginarios urbanos pueden contribuir en ese proceso de construcción social del espacio urbano. En la tercera parte avanzamos sobre lo que es nuestro interés central: los desafíos metodológicos que esta perspectiva implica. A fin de desarrollar este aspecto, primero revisamos los caminos más frecuentemente seguidos, al mismo tiempo que advertimos sobre sus limitaciones. Enseguida, planteamos una estrategia metodológica propia que denominamos hologramas espaciales ${ }^{1}$, que intenta sortear las

En otra ocasión hemos denominado a esta aproximación hologramas socio-espaciales y también hologramas socio-territoriales (Lindón, 2006b; 2007). Actualmente, hemos optado por nombrarlos simplemente como hologramas espaciales ya que nuestro concepto de espacio incluye lo social, de modo tal que así se evitaría lo reiterativo de la expresión socio-espacial. No obstante, para quienes no estén inmersos en la deriva que ha seguido el concepto de espacio en las últimas décadas (sobre todo, dentro de la Geografía Humana) podría resultar pertinente el adjetivo de socio. 
limitaciones de las aproximaciones tradicionales aunque no por ello está libre de escollos.

En suma, nos abocamos a esbozar una mirada sobre la construcción social de los lugares en la ciudad desde los imaginarios urbanos, con un interés fuertemente metodológico que se puede condensar en el siguiente interrogante general: ¿cómo estudiar la construcción social de los lugares en la ciudad con relación a los imaginarios urbanos? Sobre este interrogante dibujamos nuestra primera respuesta, que no tiene ninguna aspiración de precisión, de exclusividad ni de exhaustividad: a través de los hologramas espaciales, que constituyen una derivación de la metáfora del holograma social.

\section{La construcción social de los lugares}

La construcción social del lugar no debería comprenderse como una expresión más, o como una frase de moda. Antes bien, consideramos que su potencial analítico solo emerge cuando es considerada a la luz del pensamiento constructivista en sentido amplio. El constructivismo es una perspectiva ampliamente reconocida en la filosofía de las últimas décadas ${ }^{2}$ y en las diversas ciencias sociales. Sin embargo, ha logrado un mínimo impacto en el caso de los estudios territoriales, urbanos y los abordajes sobre la espacialidad en general. Una expresión de ello se constata al observar que los autores que se asocian usualmente al constructivismo -tales como Bateson, Gergen, Watzlawick, Maturana, Varela, Schutz, Berger, Luckmann- en principio no parecen tener vínculos evidentes con los estudios territoriales y urbanos. Sin embargo, desde hace más o menos tres décadas se han dado aportes diversos -y más o menos dispersos- en los Estudios Urbanos y Geográficos (particularmente, ciertas geografías urbanas) que están abriendo este camino. Dentro de los Estudios Urbanos se puede recordar cierta Sociología Urbana sensible

Aunque la expresión constructivismo es reciente-muchos marcan el hito inicial en 1980-, remite a una problemática del conocimiento muy antigua, como es la relación entre el objeto y el sujeto que conoce. Existen antecedentes en el mundo griego clásico, en el siglo XVII con Gianbattista Vico, en el siglo XVIII con Inmanuel Kant, a fines del XIX con William James y Friedrich Nietzche, en la primera mitad del XX con José Ortega y Gasset y Alfred Schutz, por nombrar solo algunas figuras prominentes. al pensamiento de Berger y Luckmann (Joseph, 1988), como también aquellos fragmentos de la denominada Psicología Ambiental con interés expreso en la ciudad, así como algunos enfoques -también recientes- de la Geografía Humana. Nos interesa particularmente el caso de esta última disciplina -los aportes de la Geografía Humana al constructivismo- porque su eje de análisis es el territorio y precisamente, si el constructivismo tiene un gran potencial para el estudio de la ciudad es con referencia al territorio y la espacialidad.

\section{Las geografias humanistas}

Los aportes de la geografía humana a este constructivismo se pueden ubicar en varias líneas, una de ellas corresponde a lo que ha dado en llamarse humanismo geográfico, pero también las geografías pos-estructuralistas han contribuido en este sentido. En ambos casos se viene abriendo un camino que actualmente parece fértil para el diálogo entre el pensamiento sobre la espacialidad (en sus diversas vertientes) y el constructivismo en sentido amplio. Así, algunos de los puentes entre los Estudios Urbanos y el pensamiento constructivista se vislumbran en particular en el replanteamiento del concepto de espacio - "mucho más geométrico o bien, un principio universal" (Bailly, 1989: p. 12)- en el concepto de lugar y en el de espacio vivido (espace vécu), así como en la centralidad otorgada por ciertos autores a la experiencia espacial (Buttimer \& Seamon, 1980).

En este camino, algunos geógrafos han enfatizado el papel de la negociación cotidiana de las personas en contextos concretos (Ley, 1978). En esta última perspectiva, cabe destacar el trabajo de David Ley (1978), quien planteó explícitamente y de manera temprana la construcción social de la realidad a partir del espacio. Posteriormente, este autor incorporó directamente la expresión construcción social del lugar desde varias entradas: por ejemplo, los lugares son construidos socialmente por el intercambio simbólico y recíproco entre la gente y los lugares (Ley, 1981a). Pero también, los lugares son construidos socialmente por la convergencia de la subjetividad y la intersubjetividad con la materialidad de los lugares. Dicho de otra forma, la articulación necesaria de lo subjetivo y lo objetivo de la espacialidad, los construye socialmente (Ley, 1989). 


\section{Las geografías posmodernas}

Otra línea de aportes a este constructivismo geográfico se puede identificar en torno a la obra del geógrafo sueco Gunnar Olsson. Su obra -como partícipe de las geografías posmodernas- también ha jugado un papel central en esta apertura hacia un constructivismo espacial a través de su trabajo sobre la inclusión del lenguaje, en particular los juegos del lenguaje de Wittgenstein, pero replanteados para en el estudio de la espacialidad (Olsson, 1978; 1980; 1991a; 1991b). En este sentido se pueden recordar ciertas palabras elocuentes de Olsson: "los límites del ecumene son los límites de mi mundo. Los límites de mi mundo son los límites de mi lenguaje. Los límites de mi lenguaje son pensamiento-y-acción al límite de sí mismo" (1997: p. 39). Más allá del efecto fonético que pueda tener el parafrasear territorialmente (al recurrir al ecumene) la conocida frase de Wittgenstein (los límites de mi mundo, son los límites de mi lenguaje), es indudable que Olsson con estas palabras está ampliando los límites de la perspectiva geográfica, y en consecuencia territorial, por la inclusión del lenguaje, el pensamiento y la acción junto al ecumene.

Durante mucho tiempo se asumieron varias cuestiones que estas palabras desmoronan: por un lado, la idea de que el ecumene era uno, en todo caso se asumía que cambiaba históricamente. Olsson-recuperando las ideas de John K. Wright (1947) y de Lowenthal (1961)-, respectivamente, de la terrae incognitae y las geografías personaleslo adjetiva como mi ecumene, es decir el ecumene de una persona no es el mismo que el de otra, o como dirían Wright y Lowenthal, mis territorios conocidos pueden ser desconocidos para otros. Las visiones tradicionales nos enseñaron que los límites del ecumene se definían históricamente en función de la tecnología disponible, que permitía conquistar tierras cada vez más remotas. Olsson nos dice que los límites del ecumene están dados por el lenguaje: así, los lugares sobre los que no puedo hablar, no forman parte de mi ecumene. Y por último, muy en sintonía con el constructivismo, Olsson nos recuerda que el lenguaje (en este caso los lugares de los que puedo hablar) también muestran lo que hago en esos lugares y lo que pienso de los mismos: estamos frente a una forma de construcción social del lugar por el lenguaje.
También como parte de estas geografías posmodernas que giran hacia el constructivismo geográfico se puede observar la concepción de los lugares como textos, es decir la perspectiva de la textualidad aplicada al territorio. En este caso, algunos geógrafos (Barnes \& Gregory, 1997: p. 138-144) retomaron planteamientos como el de la intertextualidad inspirados en las obras de Todorov y Bakhtin, pero nuevamente fueron interpretados con referencia al espacio. En este camino una de las ideas centrales es la que sostiene que para el habitante siempre un lugar evoca a otro lugar. Entre un lugar y otro se da una relación de copresencia. El sentido de un lugar evoca al sentido de otro lugar.

\section{Las geografias de las representaciones}

Otra línea de las miradas geográficas que fueron girando hacia el constructivismo es la que introduce el problema de las representaciones del espacio y el territorio (Bailly, 1989) y el consecuente tema de la crisis de las representaciones (Duncan \& Ley, 1993, p. 4). El tema de las representaciones espaciales en la geografía no tardó en reconocer lo que la psicología y la sociología habían observado anteriormente, es decir la crisis de las representaciones derivada del sentido literal de re-presentar como reproducción fiel de lo real (las representaciones miméticas). En términos espaciales, las miradas atentas a las representaciones espaciales también plantearon un segundo nivel de crisis y en consecuencia, de autocrítica: el de las representaciones legitimadas en la disciplina, sobre todo a través de la racionalidad cartográfica (Harley, 2005; Minca, 2002). Esta última vertiente, más que un constructivismo geográfico fue girando hacia un deconstruccionismo geográfico.

Desde la geografía francófona de las representaciones, aunque muy imbuida del pensamiento anglosajón, Antoine Bailly ha representado una voz relevante en el tránsito hacia una Geografía, primero de las representaciones y luego, de lo imaginario. En esencia, sus trabajos han significado la apertura de otra línea de avance hacia el constructivismo geográfico, expresada -entre otras- en el rechazo a las miradas que reducen el espacio a su componente material. La espacialidad de la vida social no debería reducirse a una realidad 
material, única y externa a las personas. Precisamente, el constructivismo se presenta en este caso en la centralidad de la componente no material del espacio. Antes bien, la espacialidad se debería comprender en la mezcla entre lo imaginario y lo real (Bailly, 1989):

"En un entorno histórica y socialmente dado, el individuo construye su propia realidad articulando lo estructural, lo funcional y lo simbólico; (...) el paisaje nos remite a nuestra experiencia existencial; cómo se articulan lo real y lo imaginario en cada lugar" (1989: p. 11).

\section{La geografia social compleja}

Otra línea de aportes al constructivismo, también desde las geografías francófonas, es la que se puede anclar en autores actuales como Guy Di Meo y Claude Raffestin. En este sentido -dentro de las Geografías francófonas- cabe recordar la propuesta de Claude Raffestin (1986) como parte de este largo y sinuoso camino hacia el constructivismo geográfico. Para Raffestin, el territorio es construido socialmente ya que resulta de la semiotización del espacio. En otras palabras, las sociedades, los grupos sociales, las personas le incorporan al espacio la semiósfera, es decir, el conjunto de signos culturales que caracterizan a una sociedad, y el resultado de ese proceso inacabado -llamado por Raffestin (1986) ecogénesis territorial- es el territorio. En este caso el constructivismo territorial resulta de la semiotización del espacio.

Dentro de la geografía francófona contemporánea que avanza decididamente en el constructivismo geográfico merece un lugar particular el aporte de Guy Di Meo. Este autor ha realizado la propuesta teórica más fuerte con una mirada constructivista. Su teorización se construye en la articulación del individuo (con todas las declinaciones posibles que puede tomar esta palabra: persona, sujeto, actor...), la sociedad y el espacio. $\mathrm{Su}$ aporte es esencialmente constructivista ya que en estas relaciones incluye la influencia recíproca: el espacio influye en los individuos y los individuos lo moldean. Pero también plantea la misma articulación entre el individuo y la sociedad. Por ejemplo, señala que los "lugares son vividos individualmente y socialmente producidos" (Di Meo y Buleon, 2005: p. 39). En ese juego de relaciones recíprocas constantemente destaca la importancia de lo subjetivo junto a lo objetivo, de lo material y lo no material, de lo individual y lo social, de lo espacial y lo social. Las palabras de Di Meo que siguen son elocuentes como expresión de ese constructivismo geográfico que parece marcar la pauta para los estudios territoriales del tercer milenio:

"La construcción social permanente de los territorios no puede resultar más que de una interacción poderosa entre las estructuras objetivas del espacio (obras de las sociedades) con las estructuras cognitivas (que se traducen en imágenes, representaciones y distintas ideologías) individuales, aunque con esencia social, que dan forma a la conciencia de todo ser humano. Entre estas dos instancias interactivas, generadoras de territorios, se forman vínculos de reciprocidad. El universo simbólico (ideologías territoriales, valores patrimoniales, memoria colectiva, sentimientos de identidad en particular) de las estructuras cognitivas del sujeto social encuentra un campo de referencias sólidas en las estructuras objetivas del espacio geográfico. Éstas aportan, a cambio, argumentos de identidad, hitos innumerables y capaces de restablecer la memoria colectiva para las sociedades que los producen. En el centro de este fuego cruzado de interferencias ideales y materiales, lejos de expresar rutinas invariables, las prácticas tranquilas de lo cotidiano demuestran, en forma permanente, un asombroso espíritu de invención. Son ellas las que producen sin descanso el espacio geográfico y sus territorios" (Di Meo, 1999: p. 91).

Posiblemente metáfora del fuego cruzado usada por Di Meo sea una de las expresiones más claras de este constructivismo geográfico, aun en ciernes.

\section{Cultural turn}

Todas estas líneas del constructivismo territorial que hemos repasado, han ido convergiendo en el movimiento denominado Cultural Turn que desde fines de los años ochenta atraviesa a 
la Geografía anglosajona (Philo, 1999) pero que actualmente tiene un impacto importante en los estudios territoriales latinoamericanos. Dicho Giro Cultural ha tomado como uno de sus principales ejes la incorporación de lo no-material en el estudio del espacio y la espacialidad. En estas miradas cabe destacar aportes como el de Derek Gregory que buscan la articulación de la mirada de Lacan en relación con la espacialidad (Gregory, 1995). No obstante tanto Derek Gregory, como Nigel Thrift y Don Mitchell (voces destacadas a favor de la semiótica del espacio a fines de los ochenta), después de haber impulsado la consideración del lenguaje, lo textual y lo semiótico, a mediados de los noventa proponen abandonar este camino para centrarse en las prácticas que construyen el lugar, ya que las redes de actantes se hacen y se deshacen ${ }^{3}$. Así, estos autores y sobre todo Nigel Thrift (1996), llegan a postular una vía constructivista particular, conocida como performativa del espacio. Esta perspectiva tampoco es ajena a lo que años antes desarrollara -desde la Geografía humanista- David Seamon (1979) bajo la idea de coreografías. En realidad, todas estas líneas del constructivismo territorial se aproximan en diversos aspectos, y al mismo tiempo en otro se distancian al enfatizar ciertos rasgos y no otros.

Si bien en ciencias sociales como pueden ser la sociología o la psicología social, el tema del sujeto y su punto de vista ya cuenta con tradiciones consolidadas, en el estudio de la espacialidad, el territorio y la ciudad, la situación es diferente: existen antecedentes relevantes (voces pioneras), pero distan de ser enfoques instituidos y retomados en las comunidades académicas (Lindón, 2006a). Posiblemente, una de las circunstancias que ayude a comprender estos rezagos y resistencias sea el peso que ha tenido la idea del espacio y el territorio como realidades materiales y objetivas. Aunque los aportes de muchos autores han mostrado que el espacio y el territorio también son objeto de elaboración subjetiva por parte del sujeto-habitante, las resistencias a su inclusión -más aún, de manera central- son considerables.

Cabe observar que también Guy Di Meo y Pascal Buleon han utilizado la expresión -de raigambre claramente lingüística- de actantes, en referencia al "actor en acción" (2005: p.29).
Todo lo anterior muestra que el estudio de la espacialidad urbana también puede orientarse desde el constructivismo, particularmente desde un constructivismo geográfico. En este sentido cabe recordar que uno de los presupuestos del constructivismo en general es que lo que conocemos y creemos resulta del lenguaje con el que entendemos y transmitimos nuestras percepciones del mundo. En este pensamiento se ha señalado que al hablar -en un mundo compartido siempre con otros- las personas crean la realidad. Por eso, un mismo fenómeno urbano, un mismo fragmento de ciudad o una ciudad, puede ser construida de diferentes formas en función de distintos puntos de vista (Lindón, 2007).

En nuestra concepción, el constructivismo geográfico -o espacial- asume que el sujeto habitante y también cognoscente, construye los lugares día a día, aunque esos lugares también reconfiguran las identidades de los sujetos que los habitan. Por ello, cada lugar es resultado de las acciones del sujeto sobre el mundo externo (la ciudad, en nuestro caso), dependiendo así tanto de las características del sujeto como de las del entorno en el cual se ejerce la acción. A su vez, las acciones del sujeto habitante se configuran dentro de una lógica compartida y también reconstruida constantemente. Al mismo tiempo, esos lugares así construidos modelan esas tramas de sentido y las acciones que en ellos se concretan.

\section{Los imaginarios y la construcción social de los lugares}

Todo lo anterior nos permite concebir a la ciudad como un mosaico de lugares que han sido y son construidos socialmente, en un proceso siempre inconcluso. Ese espacio urbano, con sus lugares, lleva consigo y condensa valores, normas, símbolos e imaginarios sociales. En otras palabras, todo ese mundo no material de los valores, normas, símbolos e imaginarios se objetiva en la materialidad misma de la ciudad. Como han señalado Di Meo y Buleon (2005: p. 26), los imaginarios junto con las normas y valores, realizan un proceso de cualificación ${ }^{4}$ a través del sentido, de la

\footnotetext{
4 Cabe recordar que, de acuerdo al Diccionario de la Lengua Española en su vigésima primera edición, cualifi-
} 
materialidad del mundo: los imaginarios son redes o tramas de significados específicos, reconocidas socialmente, que le otorgan cualidades a la ciudad y sus lugares. Por ser tramas de significados no pueden ser reducidos al significado que se le otorga a un elemento u objeto. Indudablemente, los imaginarios no se configuran fuera de los contextos y procesos históricos, sino dentro de ellos. Por eso tampoco son inmutables. Por ejemplo, los imaginarios urbanos actuales del miedo casi siempre se configuran a partir del miedo al otro, asumiendo que es el otro quien puede controlar la situación y en consecuencia fragiliza al yo. Asimismo, los imaginarios de la seguridad se conforman a partir del sentido de la protección y la separación del otro, que en sí se vive como protección. No obstante, estos imaginarios tienen un anclaje histórico y por ello mismo, podríamos reconstruir imaginarios urbanos de la seguridad configurados de otras formas para otros momentos de la historia.

El proceso por el cual los imaginarios urbanos cualifican a los lugares opera de manera compleja: por un lado, los imaginarios urbanos compartidos por distintos grupos, al darle cierto sentido a un lugar lo cualifican de alguna forma particular, le atribuyen ciertas características. Un ejemplo sencillo se aprecia cuando unos lugares de una ciudad son cualificados como lugares peligrosos, o lugares de mucha seguridad, o bien como lugares elitizados, o como lugares populares... Por otro lado, los imaginarios urbanos también participan del proceso de cualificar los lugares de formas específicas antes de que se haya procedido a su manufacturación en términos materiales. Por ejemplo, los imaginarios urbanos que orientan la renovación de un antiguo barrio manteniendo objetos que expresan la historia del lugar o incorporando objetos tecnológicos de última generación le otorgan unas características peculiares al lugar. Esos imaginarios urbanos orientan acciones que le imprimen a ese lugar unas características físicas que otros reconocerán y permitirán así, que el lugar sea cualificado como antiguo con una profunda historia, o bien antiguo y al mismo tiempo tecnologizado, por poner algunos ejemplos. Otro caso es el de los imaginarios urbanos que guían la

car significa "atribuir o apreciar cualidades" (RAE, 2000: p. 606). construcción de un barrio amurallado en el sentido contemporáneo de la expresión: estos imaginarios urbanos pueden impulsar la manufacturación de ese barrio con rasgos materiales particulares, que otros podrán cualificar como expresión de lugar exclusivo, lugar elitizado, lugar de acceso restringido o directamente lugar impenetrable.

No obstante, cabe señalar que este último papel de los imaginarios urbanos en la cualificación de los lugares no solo corresponde a los imaginarios que mueven a aquellos sujetos que están construyendo materialmente un barrio o dirigiendo ese trabajo, o renovando una zona de la ciudad 5 . También opera el mismo proceso en el caso de las acciones realizadas por los sujetos anónimos que -en otras escalas-introducen un objeto en un lugar, que podrá ser reconocido socialmente como expresión de una cierta cualidad. Así, esa cualidad resulta atribuida al lugar en el cual está el objeto. En este sentido, se puede considerar el caso de diversas marcas que las personas incorporan en el exterior de sus viviendas para que el lugar sea cualificado por los otros de cierta forma: los ejemplos son numerosos y diversos, pueden ir desde una placa con el nombre de la familia que allí reside, como una forma de destacar algo más que la simple identificación. Por ejemplo, se podría estar buscando el reconocimiento de una tradición familiar a partir de ese objeto-marca inscrito físicamente en la casa y simbólicamente en una tradición de sentido. Otro ejemplo, podría ser la aplicación de un icono que indique el peligro que puede suponer la violación de ese espacio privado... También suele ocurrir que la incorporación de marcas y señales en el exterior de la propiedad sea realizada por quienes no residen en ella, pero con esa inscripción buscan producir un cierto proceso de cualificación del lugar. En algunos barrios pobres de la ciudad de México se ha constatado recientemente que las casas son objeto de inscripciones en su exterior por parte de grupos delictivos. En ese caso, las marcas buscan desencadenar un proceso de cualificación no en sentido de la sociedad en términos amplios, sino una cualificación social dentro del mundo más restringido de misma la

\footnotetext{
5 Lo que correspondería al denominado Segundo Espacio de Soja (1996), es decir, el espacio que es concebido y diseñado por planificadores, urbanistas y otros agentes con
} poder. 
delincuencia. En ese caso la marca puede cualificar a la vivienda de diversas formas: por ejemplo, como vivienda difícil de robar, fácil de robar, vivienda que está deshabitada en cierta parte del día o de la semana, vivienda que ya ha sido robada... Todas esas cualificaciones pueden operar porque entran dentro de una trama de sentido extensa.

Las situaciones anteriores muestran que "el espacio es producido [construido] por el sentido y al mismo tiempo, por la experiencia social" (Di Meo \& Buleon, 2005: p. 23). Así por ejemplo, si un grupo social (ya sea pequeño o tan extenso como una nación) reconoce a un lugar como peligroso, se está frente a una construcción social del lugar a través del sentido del peligro que asume ese grupo social. Esto es un proceso en el que la intersubjetividad converge en atribuirle ese sentido -que ha sido definido socialmente con anterioridad y en relación a otros fenómenos- al lugar en cuestión. Sin embargo cabe destacar que al mismo tiempo, puede haber experiencias sociales (en tanto acontecimientos sociales que llevan consigo cuestiones materiales y también significados) allí ocurridas (una memoria del lugar) (Lindón, 2006c), o bien pueden existir formas materiales que sean parte del lugar (como el caso de las marcas antes mencionadas), que contribuyan -unas y otras, experiencias y materialidades- a otorgarle al lugar ese sentido de lo peligroso, o cualquier otro sentido.

Todos estos procesos de cualificación del lugar son realizados por los distintos sujetos sociales -en el cotidiano devenir- al hacer uso de esas tramas de significados que ellos mismos han construido y reconstruido, llamadas imaginarios urbanos. En última instancia el papel de los imaginarios urbanos en la construcción social de la ciudad se puede entender desde la idea fenomenológica: "una realidad geográfica tejida en la conciencia humana y una conciencia humana tejida en el mundo" (Di Meo \& Buleon, 2005: p. 26).

\section{¿Cómo estudiar la construcción social de los lugares?}

Los posibles caminos metodológicos para estudiar los imaginarios urbanos -y más aun, su papel en la construcción social de los lugares- pueden revisarse desde dos ángulos: los caminos instituidos por un lado y por otro, las nuevas propuestas que por su misma innovación casi siempre están inconclusas. Respecto a los primeros, los instituidos, cabe subrayar que se trata de aproximaciones de base estadística, particularmente la encuesta. La caracterización de este abordaje como frecuente, no se debe a que se haya instituido en el campo particular de los imaginarios urbanos. Más bien se trata de un instrumento frecuente e instituido en la investigación social en sentido amplio, pero que casi siempre se ha empleado para estudiar otras cuestiones, aunque ha sido aplicado también al campo de los imaginarios urbanos. Seguramente que tanto estos abordajes ya muy instituidos, como otros alternativos, presentan aspectos pertinentes. En el primer caso es innegable la virtud de llevar consigo un bagaje de conocimiento técnico acumulado, aunque no lo sea con respecto al estudio de los imaginarios urbanos en particular. En el segundo caso, las nuevas propuestas tienen el mérito de buscar aproximaciones ad hoc para estudiar los imaginarios urbanos, de atreverse a transitar por los nuevos caminos. Pero al mismo tiempo llevan consigo la debilidad propia de toda innovación, lo incierto, lo inconcluso... En última instancia, todas estas debilidades y virtudes deberán ser evaluadas en el contexto de cada investigación particular y de las trayectorias de quienes en ellas estén buscando producir nuevos conocimientos sobre el tema.

\section{Los abordajes usuales y sus limites}

En cuanto a los abordajes más instituidos nos resulta relevante revisar algunas transferencias que han supuesto estas metodologías tradicionales para el estudio de los imaginarios urbanos. La revisión de los supuestos de estas metodologías puede resultar fértil para aquellas investigaciones que las utilicen para el análisis de los imaginarios urbanos, ya que transfieren -de manera implícita- al campo de los imaginarios ideas que pueden entrar en contradicción con el sentido profundo del pensamiento constructivista y con los imaginarios mismos. Básicamente, merecería una revisión profunda todo lo vinculado al aislamiento de rasgos que siempre lleva consigo la encuesta estadística.

Las metodologías urbanas tradicionales observan el espacio urbano desde afuera de la experien- 
cia espacial, desde afuera del sujeto habitante. Por eso suelen tratar al espacio urbano como objeto, casi como cosa en el sentido durkheimiano. Esto se concreta en un supuesto ampliamente asumido, aunque poco discutido en los Estudios Urbanos, como es aquel según el cual cualquier rasgo del espacio urbano puede ser observado desde afuera, es decir, por un observador externo, y en consecuencia puede ser medido en el sentido tradicional de la expresión.

Para estas perspectivas urbanas tradicionales, el procedimiento metodológico adecuado tiene su punto de partida en la disección del objeto observado en los distintos rasgos o elementos que resulten de interés para el analista. En este proceso el analista separa unos rasgos de otros, los diferencia, los compara, todo ello a través de la definición de las conocidas variables y los posteriores procedimientos estadísticos para relacionarlas. En esencia, estos procedimientos separan rasgos casi como lo haría un procedimiento quirúrgico. Esto no impide que luego de separar, se realicen procedimientos para establecer relaciones o incluso, las multi-relaciones. Esto último es lo que frecuentemente se hace a través de los denominados modelos estadísticos multivariados.

La transferencia de estas metodologías al estudio de los imaginarios urbanos ha sido frecuente. Aunque casi nunca llega a la complejidad técnica de los procedimientos multivariados, por ello no se abandonan sus supuestos. A pesar de lo usual que ha sido esta transferencia, no deja de plantear muchas interrogantes respecto a su pertinencia.

Las dudas respecto a las posibilidades de reconstruir imaginarios urbanos con procedimientos de este tipo tienen un fundamento teórico que esbozamos a continuación. Acordamos que "El imaginario tiene necesidad del símbolo para expresarse, para salir de su condición de virtualidad, 'para existir' [...] el simbolismo requiere la capacidad imaginaria, porque el símbolo presupone la capacidad de ver una cosa que ella no es, de ver la otra, en asociación complementaria con el imaginario que tiene la facultad de poner una cosa y una relación que no existen" (Vergara, 2001: p. 51). Asimismo, también aceptamos que los símbolos se definen por su capacidad de vincular elementos inicialmente no vinculados. Esto se puede constatar desde la exploración etimológica, como lo ha hecho Lanceros (1997): la palabra símbolo parte del griego lanzar, un lanzar que, cualificado por el prefijo, inicia una búsqueda, pretende establecer un vínculo. El símbolo es por ende una pieza de unión, no es representativo como el signo, sino implicativo; no alude a un "estar por" sino a un "estar con" (Lanceros, 1997: p. 50). Por eso, Patxi Lanceros entiende al símbolo a través de la metáfora de la sutura en una herida o en una fisura, es decir, la unión de elementos no unidos inicialmente sutura la fisura. En esta perspectiva, los imaginarios vendrían a constituir -continuando con el uso de la metáfora- ese tejido extenso que resulta de múltiples suturas. Por ello, ese entramado de sentido -los imaginarios urbanos- habla de la ciudad o sus barrios, o sus calles, de ciertas formas. El imaginario urbano ha ido uniendo simbólicamente prácticas, locus, objetos y sujetos de ciertas formas, que permiten contar historias, atribuir valores y significados, imaginar futuros y reconstruir pasados...

Así, se puede afirmar que los símbolos resultan de la capacidad imaginaria de los sujetos sociales, y unen lo que no estaba unido. Esto último tiene una notoria implicación metodológica: nos podemos preguntar, si los imaginarios urbanos operan culturalmente uniendo elementos que no estaban unidos, cómo es posible que los estudiosos de los imaginarios urbanos pretendan reconstruirlos con herramientas que en esencia hacen lo contrario a la unión, vale decir, con procedimientos que cortan, fragmentan y aíslan. El caso más evidente es el de la encuesta por cuestionario. Los cuestionarios captan la realidad fragmentándola a través de las variables contenidas en las preguntas. Una variable, en esencia hace un corte preciso en la realidad, y registra ese fragmento aislado. Entonces, las preguntas del cuestionario más que tener detrás el supuesto de suturar la herida, tienen el presupuesto de producir la herida al separar o cortar. Esta es la transferencia más riesgosa que a nuestro modo de ver el problema, se suele realizar cuando se emplean metodologías instituidas, como la encuesta, para conocer imaginarios urbanos.

Estas estrategias metodológicas llevadas al campo de los imaginarios urbanos suelen encon- 
trar su razón de ser en la búsqueda de aspiraciones generalizantes. Tal vez uno de los ejemplos más claros de esto es la intención de comprender una ciudad a través de un imaginario. Frente a esto nos preguntamos: si la ciudad contemporánea es reconocida por su complejidad (incluso en el sentido etimológico de la expresión complejo: contiene muchos pliegues: ¿cómo pretender reducirla a un gran imaginario urbano o a bien a unos cuantos macro imaginarios urbanos?

El repaso de estas estrategias metodológicas, nos hace considerar que la inclusión de los imaginarios en la construcción social del lugar por parte del estudioso de la ciudad, exige la búsqueda de estrategias metodológicas alternativas de tipo denso y de espíritu comprensivo, que no separen ni aíslen elementos. En esta perspectiva planteamos la estrategia que venimos denominando hologramas espaciales.

\section{Propuestas alternativas}

Uno de los posibles caminos alternativos para desentrañar la construcción social de diferentes lugares y el papel jugado por los imaginarios, es la que venimos denominando hologramas espaciales. Esta propuesta viene a integrarse bajo esa amplia perspectiva paraguas, muchas veces difusa, como es la de investigación cualitativa. De manera más específica, se inscriben en la metáfora del holograma social, reiterada en las ciencias sociales contemporáneas. Veamos primero la metáfora del holograma social, para pasar luego al holograma espacial.

\section{... La metáfora del holograma social....}

La idea del holograma procede de la física, por eso en el contexto de las ciencias sociales y de los Estudios Urbanos en particular, solo le damos un uso metafórico. De acuerdo a la invención realizada en 1947 por el físico húngaro Dennis Gabor, la holografía es una técnica avanzada de la fotografía por la cual "en la placa fotográfica se impresionan las interferencias causadas por la luz reflejada de un objeto con la luz indirecta. Iluminada (después de revelada) la placa fotográfica con la luz del láser, se forma la imagen tridimensional del objeto original" (RAE, 1992: p. 1117). Entonces, la holografía trata de un procedimiento técnico de iluminación para hacer visible algo que de lo contrario no tiene visibilidad.

En este trabajo retomamos -de manera metafórica- esa idea del holograma para estudiar la construcción social de los lugares. Esto significa que transferimos el sentido de un procedimiento conocido aplicado a las placas fotográficas, a otro ámbito del conocimiento en el cual nos permita esclarecer un procedimiento en esencia diferente, orientado a darle visibilidad a la construcción social de diferentes lugares y al papel que en ello han jugado distintos imaginarios urbanos. En suma, es metafórico el uso que hacemos de la expresión holograma, ya que en estricto sentido no están en juego placas fotográficas, ni luces ni rayos láser. Aunque sí lo están indirectamente porque el sentido metodológico que tendrían los hologramas espaciales es el interpretativo, y la interpretación puede concebirse también como la aplicación de una fuente luminosa.

Consideramos importante destacar dos rasgos propios del holograma fotográfico que resultan reveladores para su uso como metáfora social. Uno de ellos es que cada parte contiene información sobre todo el objeto holografiado. Así, mientras que una fotografía rasgada por la mitad solo suministra información sobre la mitad del objeto que reproduce, cada uno de los fragmentos de un holograma roto sigue conteniendo información sobre todo el objeto holografiado (Navarro, 2007). El otro rasgo significativo para su uso como metáfora social, es la capacidad de lograr la imagen tridimensional a partir de una que solo es bidimensional.

Al ubicar al holograma como metáfora social, es necesario recordar que este uso en las ciencias sociales contemporáneas es cada vez más frecuente, y al mismo tiempo tiene algunos antecedentes muy destacados: por ejemplo Jean Baudrillard con su obra América (1986), Edgar Morin con su reconocido trabajo titulado Tierra Patria (1993), Jesús Ibáñez con Más allá de la Sociología: el grupo de discusión (1979) y Pablo Navarro, con su libro titulado precisamente El Holograma Social (1994). Todos estos autores -y otros- retoman el holograma metafóricamente para hablar de las sociedades contemporáneas. Puede resultar adecuado traer las 
palabras de Morin y Baudrillard, para aclarar esta metáfora. Por ejemplo, Edgar Morin ha expresado: "hoy cada uno de nosotros es como el punto singular de un holograma que, en cierta medida, contiene el todo planetario que lo contiene" (1995: p. 35). Por su parte, Jean Baudrillard emplea la misma metáfora con relación a Estados Unidos, señalando que esta nación vendría siendo un "gigantesco holograma, en el sentido en el que la información total está contenida en cada uno de sus elementos. Tómese el más humilde punto en el desierto, no importa qué calle de una ciudad del Centro-Oeste, un estacionamiento, una mansión californiana, un Burger King o un Studebaker, se tiene toda América (Estados Unidos)" (1987: p. 27).

En todos los casos, la noción del holograma social, y también la nuestra del holograma espacial, se nutre de la idea seminal que planteara Borges con respecto al Aleph: "es uno de los puntos del espacio que contienen todos los puntos" (Borges, 2002: p. 187), es decir aquella esfera de Pascal infinita, cuyo centro está en todas partes, pero la circunferencia en ninguna (Borges, 1951: p. $16)^{6}$. El Aleph es ese microcosmos complejo en el cual todo está presente, o bien el lugar en el cual están presentes todos los lugares 7 . De manera más reciente, la idea del Aleph volvió al escenario con la conocida propuesta de Edward Soja (1996) de concebir a la ciudad de Los Ángeles como el Aleph, es decir que esta ciudad -una postmetrópolis en el discurso de Soja- sería la ciudad que contiene a todas las ciudades y al mundo en su conjunto. Seguramente que la arqueología del pensamiento podría encontrar otros parentescos y filiaciones del holograma social, tanto ascendentes como descendentes. Solo por mencionar uno de ellos, se puede recordar la iluminación profana de Walter Benjamín. No obstante, esa exploración nos alejaría de nuestro objetivo.

Ahora bien, este uso -francamente explosivo- de la figura del holograma en las ciencias sociales merece traer la advertencia que planteara Pablo Navarro

\footnotetext{
6 La esfera de Pascal fue retomada por Jorge Luis Borges para referir al universo visto como una esfera infinita.

Por esto, Borges observó que el Aleph es al espacio, lo que el infinito es al tiempo.
}

(2007): si se concibe la noción del holograma como la copia o mimesis entre el todo y las partes, se corre el riesgo del malentendido. Esta forma errónea de concebir el holograma es la que usualmente se encuentra cuando se plantea que los individuos han interiorizado a la sociedad y la reproducen. Para Navarro esa forma de aplicar el holograma a lo social, confunde su esencia ya que las partes no copiarían o reproducirían el todo social, sino que lo constituyen (Navarro, 1994: p. 304). Las partes serían asíla causa del orden social, que solo es su emergente y no una reproducción en pequeña escala.

En el caso de la propuesta de Jesús Ibáñez es necesario subrayar que tuvo un sentido más metodológico que las previas, sin por ello negar el trasfondo teórico-epistemológico de su concepción sobre el holograma social. Para este autor el holograma expresa la esencia del grupo de discusión, mientras que el fotograma podría ser la metáfora de la encuesta estadística. Esto se constata cuando se considera cualquier fragmento de discurso, resulta que siempre contiene la esencia de lo dicho. Esto se debe a que el estilo y el sentido profundo del discurso, está presente en cada una de sus frases. Por eso, el grupo de discusión sería holográfico. Mientras que en la encuesta estadística cada parte no contiene más que esa parte. Así, Ibáñez recuerda que en la encuesta las unidades de información son independientes de las otras y solo hablan de sí, por eso en el análisis es necesario "unirlas con el cemento lógico del análisis estadístico" (Ibáñez, 1979: p. 265).

\section{...Los hologramas espaciales...}

Dentro de esta perspectiva del holograma social, la propuesta que planteamos para estudiar la ciudad y sus lugares a través de los imaginarios urbanos, la denominamos hologramas espaciales. Se enfatiza la componente espacial, que estaba presente en la idea original del Aleph borgiano pero que se desdibuja en el holograma social. Así, nuestro holograma espacial tiene la aspiración de constituirse en un recurso metodológico de ese constructivismo geográfico en ciernes, pero también en notorio avance.

El holograma espacial sería un escenario situado en un lugar concreto y en un tiempo igual- 
mente demarcado, con la peculiaridad de que en él están presentes otros lugares que actúan como constituyentes de ese lugar. Esos otros lugares traen consigo otros momentos o fragmentos temporales, otras prácticas y actores diferentes aunque también pueden ser semejantes a las que se están realizando en ese escenario. Indudablemente no consideramos adecuado llevar la metáfora holográfica al extremo como para señalar que un holograma espacial sea un escenario en el cual estén presentes todos los lugares, como sería la noción del Aleph borgiano. La idea del todo resultaría inasible como aproximación teórica y metodológica. En cambio, nos resulta pertinente la del escenario en el cual están presentes otros lugares, pero que hacen a la construcción e identidad de ese lugar.

Un planteamiento de este tipo, y que pretenda ir más allá del ensayismo, de inmediato amerita un interrogante concreto: ¿`cómo están presentes otros lugares en un lugar? Sin dudas, esto solo puede ser posible a través de las experiencias espaciales de los actores que están en ese escenario. Así, aun cuando los actores de ese escenario estén en ese aquí y ahora, interactuando con otros actores en un mundo de sentido intersubjetivo, o como diría Pablo Navarro (1994: p. 302), transubjetivo, en ellos están otras experiencias espaciales vividas. En suma, los otros lugares son traídos a ese escenario (un lugar) a través de las experiencias vividas en esos otros lugares por los sujetos que actúan allí.

Dado que esta propuesta pretende tener un sentido metodológico, entonces un aspecto importante será lo que hace a la identificación de estos hologramas espaciales por parte del estudioso de la ciudad. En otros términos ¿`cómo identificar estos hologramas? Sin lugar a dudas sería posible reconstruir, hallar, demarcar estos hologramas de diversas formas. Una de ellas podría ser la propuesta de Jesús Ibáñez, a través del grupo de discusión (Ibáñez, 1979). Otra podría ser a través de fotografías. Por ejemplo, Néstor García Canclini ha recurrido a la estrategia de las fotografías de fragmentos de la ciudad para reconstruir imaginarios urbanos. Aunque este autor no recurre a la idea del holograma de manera explícita, su estrategia fotográfica podría ser otra forma de reconstrucción de hologramas espaciales (García Canclini 1996; García Canclini et al., 1997). En nuestra propuesta, nos interesa el desafío de identificar y demarcar estos hologramas en relatos de vida de habitantes y/o transeúntes de los distintos lugares y fragmentos de la ciudad. De esta forma, el trabajo metodológico del estudioso de la ciudad iniciaría con la producción de los relatos de vida de distintos urbanitas, con una componente espacial explícitamente incorporada por el narrador en su discurso.

Los relatos de vida vendrían a constituir para el investigador un corpus extenso y materia de interpretación. El primer nivel interpretativo que le plantean estos discursos al investigador ocurre en la situación misma en la cual se está produciendo el relato. Sin embargo, aquí nos referiremos a la interpretación posterior a la que ocurre en ese contexto interaccional entre el narrador y el investigador. Nos referimos a la interpretación en la cual se embarca el investigador una vez que ese discurso ha sido transformado en un texto ${ }^{8}$. Esa interpretación se inicia con la identificación de escenarios holográficos en el texto. Dichos escenarios, en estricto sentido, corresponden a circunstancias banales en apariencia, pero de gran valor metodológico porque condensan elementos claves acerca de la construcción del sentido del lugar.

Estos escenarios son construidos narrativamente desde una pauta que podríamos denominar principio de clausura, en tanto poseen un inicio, el desarrollo de cierto acontecimiento, y un cierre. Sin duda, esta clausura no implica aislamiento y hermeticidad. Antes bien, son porosos: cada escenario se conecta con otros directamente a través del hilo narrativo, y también indirectamente a través de experiencias vividas.

Esta construcción narrativa es posible porque el lenguaje materializa el flujo de la vida social, le da una forma y lo cristaliza en ella, aun cuando lo cotidiano sea un discurrir que nunca se detiene ni adopta formas estables, sino formas cambiantes. Las formas lingüísticas, las palabras empleadas, le dan formas particulares a lo multiforme que es lo vivido (Pratt, 1997; Mondada, 2000; Nogué \& Villanova, 1999). Así como la placa fotográfica inmoviliza la vida social que fluye continuamen-

8 Cabe aclarar que aquí la transformación del relato en un texto resulta del procedimiento técnico de transcripción. 
te, la narrativa hace lo propio pero a través de las formas lingüísticas empleadas: las palabras escogidas inmovilizan lo vivido. Entonces, cuando el estudioso de la ciudad y sus lugares interpreta fragmentos del lenguaje, puede captar momentos de la vida social, capturar el instante dentro del flujo, en el sentido de Bergson. En términos de un constructivismo geográfico, esto nos permite captar esos lugares que pueden no ser visibles -paisajes invisibles- para quien no participa de cierta experiencia (Lindón, 2007), o bien pueden ser paisajes fugaces como aquellos de los que habla Hiernaux (2007), que en última instancia son instantes del flujo de la vida social.

En los hologramas espaciales, el narrador refiere a lugares y prácticas concretas que allí se despliegan, verdaderos escenarios espacio-temporales de la vida cotidiana (Lindón, 2006a, 2006b). Por medio de las prácticas la persona se apropia del lugar para distintos fines, compartiéndolo e interactuando con otros que convergen en el lugar. Sin embargo, el holograma espacial no es un simple relato de prácticas y lugares, o un relato de simples escenarios en los que se despliegan prácticas. Es un relato de prácticas, lugares y escenarios que contiene dentro de sí y de manera encapsulada, otros lugares, sentidos de los lugares, intencionalidades de los habitantes de esos lugares, simbolizaciones de los lugares y del quehacer que en ellos se concreta.

Estos escenarios tendrán un potencial holográfico en la medida en que pueden ir adquiriendo profundidad a través de la interpretación y así dar cuenta de dos cuestiones centrales: una es la identificación de esos otros lugares que hacen a la construcción del lugar en el cual está anclado situacionalmente ese escenario. La segunda cuestión serían las peculiaridades de esa construcción del lugar. La identificación de estos escenarios holográficos es una tarea compleja y de esencia interpretativa. Eso implica que no se pueden proponer estrategias ni menos aun recetas, para reconocerlos. No obstante, cabe observar que en un mismo relato dos analistas podrán reconocer diferentes escenarios.

Una vez identificados esos escenarios holográficos una de las tareas centrales será la reconstrucción de las características bidimensionales del lugar, es decir todo aquello que le da la apariencia visible al escenario: las formas espaciales y las prácticas espacio-temporales allí ancladas aun cuando sea de manera circunstancial. Reconstruido bidimensionalmente el lugar, el desafío metodológico siguiente será iluminarlo-como diría Jesús Ibáñez, con la luz coherente del láser (1979)- para reconstruir el lugar tridimensionalmente. La imagen tridimensional del lugar resultaría de la incorporación de los significados atribuidos al lugar. En otras palabras, la imagen adquiere la profundidad (la tridimensionalidad), cuando las formas espaciales y los haceres (las prácticas) son reconocidos con sus significados, incluso reconociendo los imaginarios urbanos en los cuales se inscriben esos significados. Para ello se debe descifrar y decodificar lo que está detrás de las palabras, es decir los significados más profundos y su entretejido en tramas de sentido.

La interpretación del escenario holográfico hasta aquí planteada está sobre todo anclada en el escenario en sí mismo. Sin embargo, esa tarea interpretativa debería ampliarse. Una forma de profundizar la interpretación espacial es a través del reconocimiento de otros lugares que el habitante o transeúnte del lugar asocie con ese lugar, y que de alguna forma vengan a contribuir a su construcción social particular.

En este nivel de interpretación espacial ampliada también cabe preguntarnos si para el narrador, el lugar reconoce una memoria de acontecimientos pasados asociados a ese lugar. Eso será relevante porque es posible que la memoria del lugar que reconozca el sujeto resulte entretejida de alguna manera en la construcción presente del lugar.

Por último, este nivel interpretativo ampliado puede incorporar interrogantes acerca de las redes de lugares con los cuales el habitante contrasta -directamente o de forma implícita- este lugar. Esas redes de lugares que el sujeto emplea en un proceso de espejeo entre lugares, son fundamentales porque es en relación con esos otros lugares cuando se terminan de configurar los significados atribuidos a un lugar en el presente. Estas redes o conexiones entre lugares se establecen a través de las experiencias de vida del sujeto: son lugares que integran el acervo de experiencias espaciales de un habitante (Di Meo, 2000b; 1999). 
La potencialidad interpretativa de los hologramas espaciales no debe negar que se trata de un recurso metodológico inscripto en la lógica del rompecabezas necesariamente incompleto, la lógica de los fragmentos densos pero siempre parciales. En última instancia, es una forma de inmersión en el análisis de los significados espaciales en contextos específicos (Eyles, 1988). Precisamente, su valor radica en que no es único, sino singular.

\section{Reflexiones finales}

El constructivismo tiene muchas corrientes, sin embargo todas tienen en común la consideración del sujeto cognoscente como constructor del conocimiento. El conocimiento es el resultado de la acción del sujeto sobre la realidad y está dado por las propiedades del sujeto y de la realidad. El sujeto almacena su conocimiento de la realidad mediante distintos tipos de entidades de distinta naturaleza: los esquemas, los conceptos y las representaciones, los imaginarios... Uno de sus presupuestos básicos es que cuanto sabemos y creemos es fruto del lenguaje con que comprendemos y transmitimos nuestras percepciones y que, sobre una misma realidad, pueden darse diferentes puntos de vista, todos ellos igualmente válidos. El constructivismo geográfico reivindica estas ideas y reconoce la acción del sujeto para construir los lugares, no solo materialmente sino también a través del conocimiento sobre ellos que acumula, a través de los valores asignados a los diferentes lugares, a través de esas tramas de sentido complejas que van tejiendo las personas en interacción, llamadas imaginarios, y que en última instancia dotan a los lugares de ciertos atributos, los cualifican.

En esta perspectiva de acercamiento a la ciudad y sus lugares, los hologramas espaciales son una perspectiva metodológica que busca hacer emerger imaginarios urbanos que cuentan la ciudad y sus lugares (o sus fragmentos) de ciertas formas peculiares.

Los hologramas espaciales permiten comprender los diversos planos de la realidad que participan en la construcción social de un lugar bajo características particulares. Incluso, pueden evidenciar como elementos ausentes, elementos que han desaparecido del mundo material pero que perviven en la memoria espacial, o elementos de lugares lejanos, pueden estar construyendo a un lugar de cierta forma.

La perspectiva metodológica del holograma espacial desafía las bases mismas de la investigación urbana, ya que en vez de estudiar el fenómeno en su extensión (por ejemplo, ampliando el universo de observación y medición), asume estudiarlo en las distintas capas o planos, pero dentro de una misma situación.

El holograma espacial es una propuesta metodológica abierta a la interpretación espacial en dos planos: uno, el del lugar como realidad localizada y otro, el del lugar como realidad desplegada en una red de lugares interconectados a través de lo vivido, que puede integrar lugares distantes.

Esto puede entenderse como una expresión de la intertextualidad espacial: un lugar evoca otro lugar y esas cadenas de evocaciones también forman parte de una trama de sentido, es decir de ciertos imaginarios. Por ejemplo, un lugar para un sujeto puede permitirle evocar un lugar de su infancia, o un lugar de un momento pasado de su trayectoria biográfica que es cualificado como lugar tranquilo, lugar que le permitió estar en contacto con la naturaleza, lugar protegido. Esas evocaciones se anclan en lo vivido por el sujeto en el pasado y también en rasgos que percibe como semejantes a los que forman parte del escenario en el cual ubica una situación holográfica, posterior a aquellas vivencias evocadas, pero pasada, o bien presente. Pero esas evocaciones también se anclan en un horizonte de sentido más amplio que legitima la evocación de cierto tipo de lugares, por ejemplo los lugares de la infancia, o de los lugares del pasado representativos de la tranquilidad frente a la agitada vida urbana actual, o bien la evocación de lugares naturales frente a los lugares habitados en una ciudad en la cual la naturaleza fue siendo acorralada gradualmente.

Por todo ello, los hologramas espaciales permiten comprender-al menos parcialmente-algunas formas de relación del sujeto con su espacio de vida que van más allá de una situación particular u otra, aun cuando el holograma siempre parte de un escenario particular y perfectamente demarcado. 
En otras palabras, los hologramas espaciales tienen la virtud de dar cuenta del cruce de la espacialidad situacional y particular (lo único, lo específico de un escenario) con espacialidades que se reiteran en otros lugares y otros escenarios, así como a través del tiempo, sin que ello suponga aspiraciones de generalización. En última instancia, los hologramas espaciales nos permitirían comprender el papel de diferentes imaginarios urbanos en la construcción social de los lugares concretos pero dentro de un horizonte de singularidad -entendida como el cruce de lo particular y lo general, o de lo individual y lo social- por el cual esas pautas podrán reconocerse en otros escenarios.

\section{Referencias bibliográficas}

Bailly, A. (1989). Lo imaginario espacial y la geografía: en defensa de la geografía de las representaciones. Anales de Geografía de la Universidad Complutense, 9, 11-19.

Barnes, T. \& Gregory, D. (1997). Textuality and human geography. En T. Barnes \& D. Gregory (Eds.). Reading in human geography: the poetics and politics of inquiry. (pp. 138-144). London: Arnold.

Baudrillard, J. (1987). América. Barcelona: Anagrama.

Borges, J. L. (1951). La esfera de Pascal. Obras completas, (Vol. 7). Buenos Aires: Emecé.

Editorial.

(2002). El Aleph. Madrid: Alianza

Buttimer, A. \& Seamon, D. (1980). The human experience of space and place. New York: St. Martin Press.

De Castro, C. (1997). La geografía en la vida cotidiana. Barcelona: Ediciones del Serbal.

Di Meo, G. (1999). Géographies tranquilles du quotidien: une analyse de la contribution des sciences sociales et de la géographie à l'étude des pratiques spatiales. Cahiers de géographie du Québec, 43, 118, 75-93.

Di Meo, G. \& Buleon, P. (2005). L'espace social: lecture géographique des sociétés. París: Armand Colin.

Duncan, J. \& Ley, D. (1993). Introduction: representing the place of culture. En J. Duncan \& D. Ley (Eds.). Placelculture/representation (pp. 1-24). London: Routledge.
Entrikin, J. N. (1991). The betweenness of place: towards a geography of modernity. Baltimore: Johns Hopkins University Press.

Eyles, J. (1988). Interpreting the geographical world. En J. Eyles y D. Smith (Eds.). Qualitative methods in human geography (pp. 1-16). Oxford: Polity Press-Basil Blackwell.

García Canclini, N. (1997). Imaginarios urbanos. Buenos Aires: EUDEBA.

García Canclini, N., Castellanos, A. \& y Mantecón, A. R. (1996). La ciudad de los viajeros: travesías e imaginarios urbanos, México 19402000. México: Grijalbo.

Gregory, D. (1995). Lefebvre, Lacan and the production of space. En G. Benko \& U. Strohmayer (Eds.). Geography, history and social sciences (pp. 15-44). Dordrecht: Kluwer Academic Publishers.

Harley, B. (2005). La nueva naturaleza de los mapas. México: FCE.

Hiernaux, D. (2007). Paisajes fugaces y geografías efímeras en la metrópolis contemporánea. En J. Nogué (Ed.). La construcción social del paisaje (pp. 237-258). Madrid: Editorial Biblioteca Nueva.

Joseph, I. (1988). El transeúnte y el espacio urbano. Barcelona: Gedisa.

Lanceros, P. (1997). La Herida Trágica. Barcelona: Anthropos.

Lévy, J. \& Lussault, M. (Dir.) (2000). Logiques de l'espace, esprit des Lieux: géographies à Cerisy. París: Belin.

Ley, D. (1978). Social geography and social action. En D. Ley \& M. Samuels (Eds.). Humanistic geography: prospects and problems (pp. 41-57). London: Croom-Helm.

(1981a). Behavioural geography and the philosophies of meaning. En K. Cox \& R. Golledge (Eds.). Behavioural problems in geography revisited (pp. 209-230). London: Methuen.

(1981b). Cultural/humanistic geography. Progress in human geography, 5, 249-257.

(1988). Interpretative social research in the inner city. En J. Eyles (Ed.). Research in human geography (pp. 121-138). Oxford: Basil Blackwell.

(1989). Fragmentation, coherent and the limits to theory in human geography. En 
A. Kobayashi \& S. Mackenzie (Ed.). Remarking human geography (pp. 227-244). London: Unwin Hyman.

Lindón, A. (2006a). Geografías de la vida cotidiana. En D. Hiernaux \& A. Lindón (Dirs.). Tratado de Geografía Humana (pp. 477-536). Barcelona: Anthropos-UAM-I. (2006b). La espacialidad de la vida cotidiana: hologramas socio-territoriales de la cotidianidad urbana. En J. Nogué \& J. Romero (Edits.). Las otras geografias (pp. 425446). Valencia: Ed. Tirant Le Blanch.

(2006c). Del suburbio como paraíso a la espacialidad periférica del miedo. En A. Lindón, M. A. Aguilar \& D. Hiernaux (Coord.). Lugares e imaginarios en las metrópolis (85-106). Barcelona: Anthropos.

(2007). La construcción social de paisajes invisibles y del miedo. En J. Nogué (Ed.). La construcción social del paisaje (pp. 213-236). Madrid: Editorial Biblioteca Nueva.

Louiset, O. (2001). Les villes invisibles. L'information géographique, 653.

Lowenthal, D. (1961). Geography, experience and imagination: towards a geographical epistemology. Annals of the association of american geographers. 51, 3, 241-260.

Minca, C. (2002). Más allá del posmodernismo: viaje a través de la paradoja moderna. Documents d'analisi geografica, geografies dissidents, 40, 45-68.

Mondada, L. (2000). Décrire la ville: la construction des savoirs urbains dans l'interaction et dans le texte. París: Anthropos.

Morin, E. (1990). L'homme domine-t-il sa planète? La pensée aujourd'hui, 2, 44-45.

(1995). Tierra Patria. Buenos Aires: Nueva Visión.
Navarro, P. (1994). El holograma social: una ontología de la socialidad humana. Madrid: Siglo XXI.

(2007). El holograma social. Diccionario crítico de ciencias sociales. Madrid y México: Editorial Plaza y Valdez.

Nogué, J. \& Villanova, J. L. (Eds.) (1999). España en Marruecos (1912-1956): discursos geográficos e intervención territorial. Lleida: Editorial Milenio.

Philo, C. (1999). Más palabras, más mundos: reflexiones en torno al 'giro cultural' y a la geografía social. Documents d'analisi geografica, 34, 81-99.

Pratt, G. (1997). Spatial metaphors and speaking positions. En T. Barnes \& G. Dereck (Eds.). Reading in human geography: the poetics and politics of inquiry (pp. 168-172). LondonNueva York: Arnold.

RAE (2000). Diccionario de la lengua española (21 ${ }^{\text {a }}$ Ed.). Madrid: Espasa.

Raffestin, C. (1986). Écogénèse territoriale et territorialité. En F. Auriac \& R. Brunet (Dir.). Espaces, jeux et enjeux (pp. 175-185). París: Fayard.

Seamon, D. (1979). A geography of the lifeworld. New York: St. Martin's Press.

Soja, E. (1996). Thirdspace. Journey to Los Angeles and other real-and-imagined places. Mass: Ed. Blackwell.

Thrift, N. (1996). Spatial formations. Londres: Sage.

Varela, F. J. (2006). Conocer las ciencias cognitivas: tendencias y perspectivas. Cartografia de las ideas actuales. Barcelona: Gedisa.

Vergara Figueroa, A. (Coord.) (2001). Imaginarios: horizontes plurales. México: CONACULTA.

Wright, J. K. (1947). Terrae incognitae: the place of imagination in geography. Annals of the association of american geographers, 37, 1-15. 